\title{
Effect of inoculum size on the in-vitro susceptibility to $\beta$-lactam antibiotics of Moraxella catarrhalis isolates of different $\beta$-lactamase types
}

\author{
S. F. YEO and D. M. LIVERMORE
}

Department of Medical Microbiology, The London Hospital Medical College, Turner Street, London E1 2AD

\begin{abstract}
Summary. The effect of inoculum size on the results of agar dilution MIC tests was assessed for 20 Moraxella catarrhalis isolates with BRO-1 enzyme, 20 with BRO-2 enzyme and 15 isolates that did not produce $\beta$-lactamase. The compounds tested were ampicillin, coamoxiclav, cefaclor, cefixime and cefetamet, and the inocula were $10^{4}, 10^{5}, 10^{6}$ and $10^{7}$ $\mathrm{cfu} /$ spot. The MICs of ampicillin for BRO-1 and BRO-2 producers were consistently higher than those for non-producers at inocula of $10^{7} \mathrm{cfu} /$ spot but overlapped with those for nonproducers at lower inocula. A small $\beta$-lactamase-related inoculum effect was seen with coamoxiclav; small inoculum effects also occurred with cefaclor and cefixime but were not related to enzyme presence or type. MICs of cefetamet were the least affected by the inoculum size. For all the compounds, the degree of correlation between MICs and the inhibition zones observed in disk diffusion tests was independent of the inoculum used in the MIC tests. These data suggest that high inocula should be used to determine MICs of ampicillin for $M$. catarrhalis but that this precaution is unnecessary with the cephalosporins tested or with coamoxiclav.
\end{abstract}

\section{Introduction}

Over $80 \%$ of Moraxella catarrhalis isolates from many countries produce $\beta$-lactamases of the BRO- 1 or BRO-2 types. ${ }^{1,2}$ Enzyme producers are clinically resistant to ampicillin but some, especially those with BRO-2 enzyme, appear relatively sensitive in MIC tests. ${ }^{3}$ The failure of such tests to detect ampicillin resistance may reflect the use of low inocula. Inoculum effects have been observed for $M$. catarrhalis with several $\beta$-lactam agents, including ampicillin, ${ }^{4,5}$ but their relationship to $\beta$-lactamase type has not been defined.

Inoculum effects also merit investigation for the newer oral cephalosporins, such as cefixime. Although these compounds are considerably more stable than ampicillin to BRO enzymes, they often appear two- to four-fold less active against enzyme-producers than non-producers in MIC tests with inocula of $10^{4}$ cfu/spot. ${ }^{2,6}$ Such behaviour suggests slight $\beta$ lactamase lability, which might be reflected in inoculum-dependent susceptibility.

In this investigation, the effect of inoculum size on the susceptibility of $M$. catarrhalis to ampicillin and cephalosporins was examined in relation to $\beta$ lactamase pattern.

\section{Materials and methods}

\section{Bacterial strains}

The $55 M$. catarrhalis isolates studied were collected during a survey in $1991 ; 20$ had BRO-1 enzyme, 20 had BRO-2 enzyme and 15 lacked either $\beta$-lactamase, as judged by iso-electric focusing. $M$. catarrhalis control strains ATCC 25238 ( $\beta$-lactamase-negative), Ravasio $\left(\mathrm{BRO}-1^{+}\right)$and $1908\left(\mathrm{BRO}-2^{+}\right)$were tested in parallel.

\section{Media and antibiotics}

Media, supplements and antibiotic-containing disks were from Unipath Ltd (Basingstoke, Hants). Coamoxiclav, comprising amoxycillin and clavulanate in a 2:1 ratio, was supplied as Adatabs by Mast Laboratories Ltd (Merseyside); cefaclor was from Sigma (St Louis, MO, USA); cefixime from Lederle Laboratories, (Gosport, Hants) and cefetamet from Roche Products, (Welwyn Garden City, Herts).

\section{MIC determinations}

Cultures were grown for $5 \mathrm{~h}$ in brain-heart infusion broth supplemented with Fildes' extract $5 \%$. These suspensions, and serial 10 -fold dilutions prepared from them, were deposited by a Denley multipoint in- 


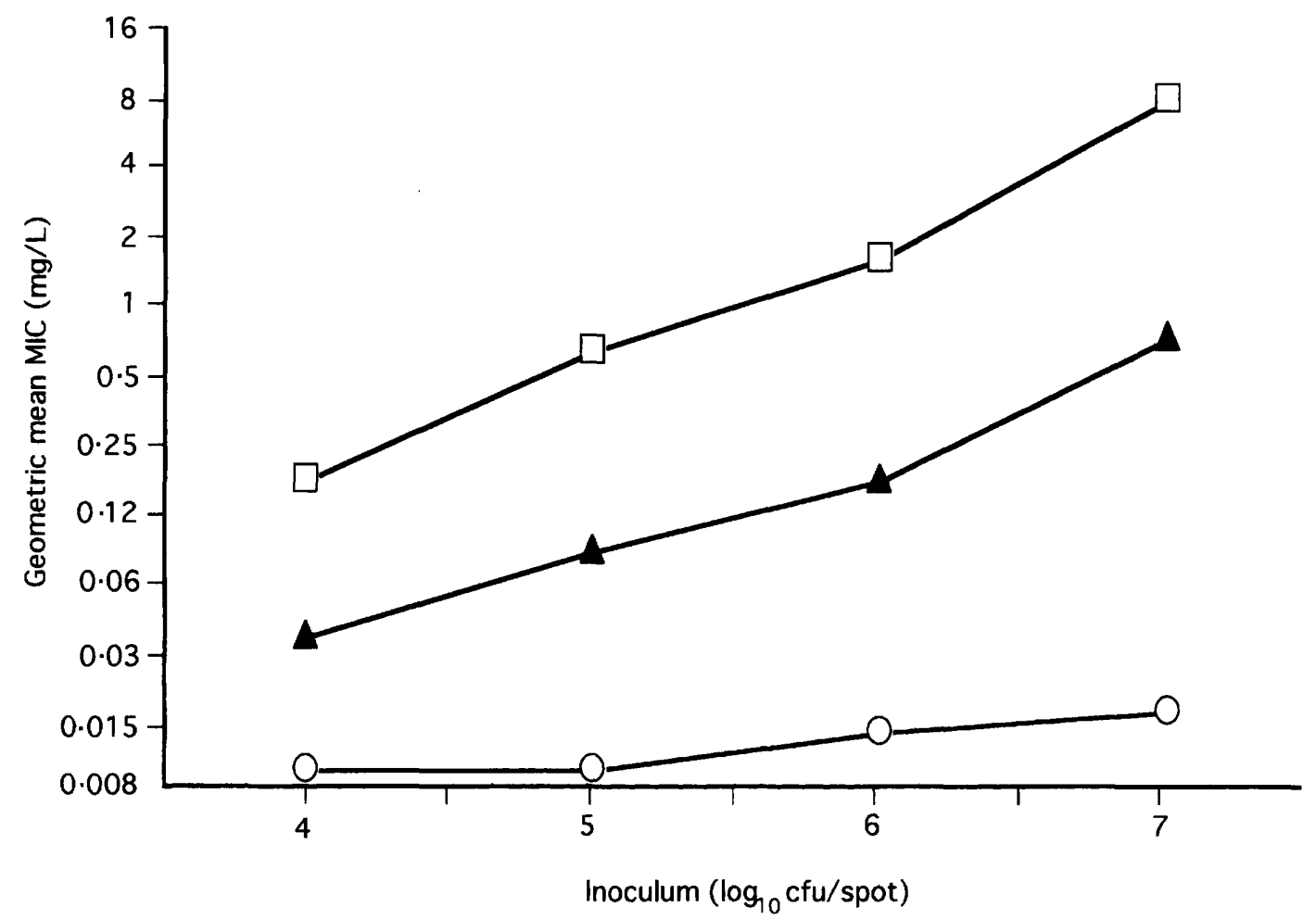

Fig. 1. Relationship between inoculum size and MIC of ampicillin for $M$. catarrhalis isolates with BRO-1 enzyme (- $\square-$, BRO-2 enzyme ( $-\mathbf{\Delta}-$ ) and no $\beta$-lactamase $(-\mathrm{O}-$ -

oculator on to DST agar containing lysed horse blood $0.25 \% \mathrm{v} / \mathrm{v}$ and antimicrobial agents at concentrations covering the range $128-0.008 \mathrm{mg} / \mathrm{L}$ in two-fold steps. The undiluted suspensions gave inocula of $10^{7} \mathrm{cfu} /$ spot and the dilutions gave inocula of $10^{6}, 10^{5}$ and $10^{4}$ $\mathrm{cfu} /$ spot. Viable counts were checked on a random sample of the inocula. All plates were incubated at $37^{\circ} \mathrm{C}$ in an atmosphere containing $\mathrm{CO}_{2} 5 \%$.

\section{Disk susceptibility tests}

Cultures were grown as for MIC tests, diluted 1 in 100 in peptone water, and then swabbed on to plates containing DST agar supplemented with lysed horse blood $0.25 \% \mathrm{v} / \mathrm{v}$. The following disks were applied to the agar surface: ampicillin $2 \mu \mathrm{g}$, co-amoxiclav $2+1 \mu \mathrm{g}$, cefaclor $30 \mu \mathrm{g}$, cefixime $5 \mu \mathrm{g}$ and cefetamet $10 \mu \mathrm{g}$. The inoculation procedure gave rise to semiconfluent growth, and zone diameters were read to the nearest millimetre after overnight incubation at $37^{\circ} \mathrm{C}$ in $\mathrm{CO}_{2} 5 \%$.

\section{Statistical analysis}

Correlation coefficients between inhibition zone diameters and logarithms of MICs at different inocula were calculated by the method of least squares.

\section{Results}

\section{MICs}

The $\beta$-lactamase-positive $M$. catarrhalis isolates showed a large inoculum effect with ampicillin, such that the increase in the geometric mean MIC of ampicillin between inocula of $10^{4}$ and $10^{7} \mathrm{cfu} / \mathrm{spot}$ was 64-fold for BRO-1 producers and 16-fold for BRO-2 producers, compared to only two-fold for $\beta$-lactamasenegative isolates (fig. 1). At an inoculum of $10^{7}$ $\mathrm{cfu} /$ spot, all the $\beta$-lactamase-producing isolates were less susceptible to ampicillin than non-producers and virtually all the BRO-1 producers were more resistant than the BRO-2 producers. At inocula of $10^{4}$ and $10^{5}$ $\mathrm{cfu} /$ spot the MIC distributions for these three groups of isolates substantially overlapped one another (fig. 2).

At an inoculum of $10^{4} \mathrm{cfu} / \mathrm{spot}$, BRO-1 producers tended to be two- to four-fold less susceptible to coamoxiclav, cefaclor and cefixime than were $\beta$ lactamase non-producers or those with BRO-2 enzyme. MICs of these compounds rose as the inoculum was increased, but only with co-amoxiclav was this effect greater for $\beta$-lactamase producers than for nonproducers (table I). For cefixime and cefaclor, the MICs rose about two- to eight-fold for all isolates, regardless of $\beta$-lactamase production. MICs of cefetamet were unrelated to $\beta$-lactamase presence or type and showed the smallest inoculum effect of any compound tested.

\section{Correlation of inhibition zones with MICs}

Regardless of the inoculum size, the correlation coefficients were consistently good for ampicillin, co-amoxiclav and cefixime and consistently poor for cefaclor and cefetamet (table II). Only with cefaclor did the correlation coefficient consistently increase as the MIC test inoculum was raised, though the actual 

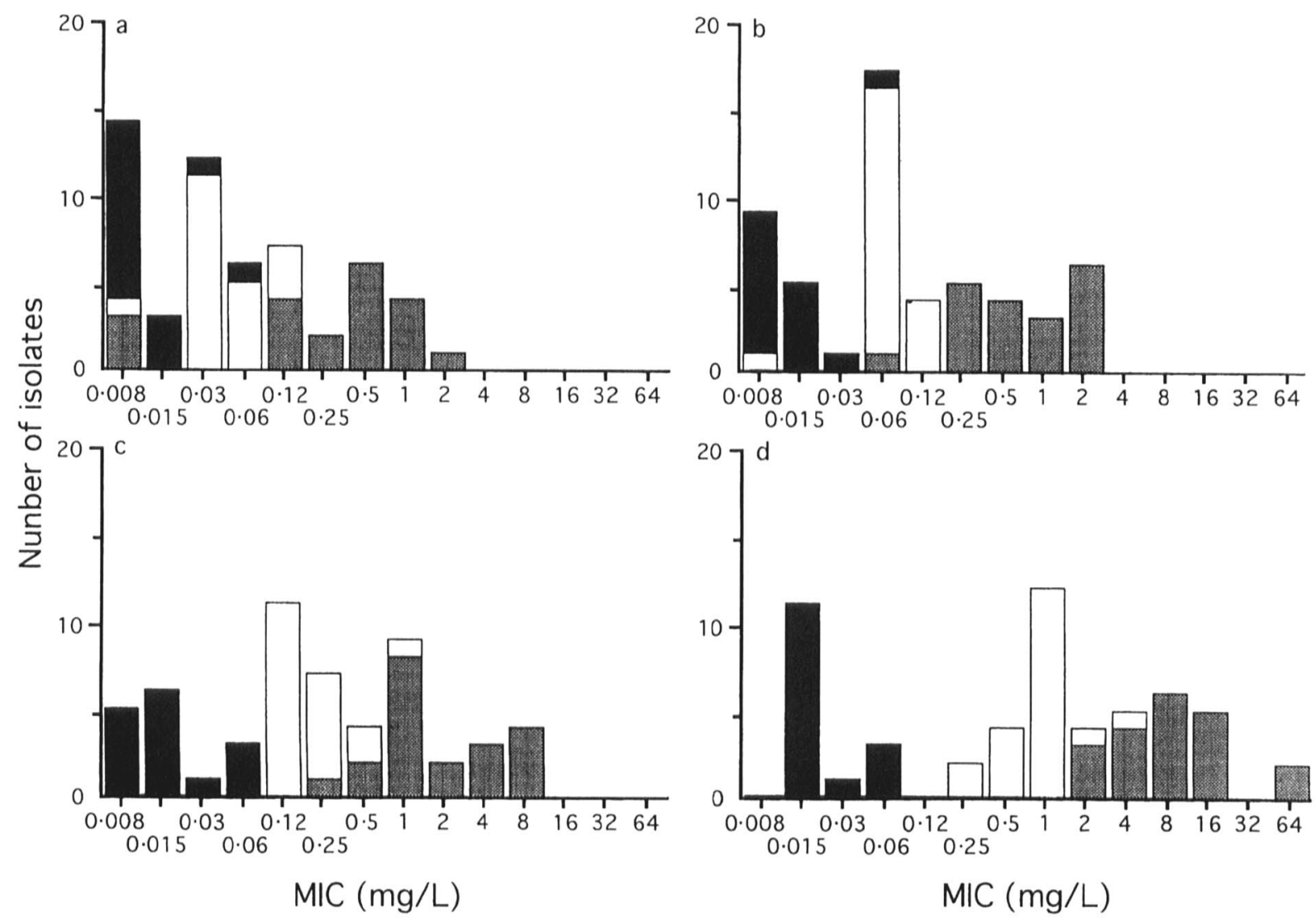

Fig. 2. Distribution of MICs of ampicillin for $M$. catarrhalis isolates with BRO-1 enzyme (圈), BRO-2 enzyme ( $\square$ ) or no $\beta$-lactamase ( $\square$ ) at inocula (cfu/spot) of: $\mathbf{a}, 10^{4} ; \mathbf{b}, 10^{5} ; \mathbf{c}, 10^{6} ; \mathbf{d}, 10^{7}$.

degree of correlation remained poor even at the highest inoculum tested.

\section{Discussion}

Inoculum effects occur widely in titrations of $\beta$ lactam antibiotics against $\beta$-lactamase-producing bacteria. In the case of $\beta$-lactamase-producing $M$. catarrhalis, Percival et al. ${ }^{4}$ reported a profound in- oculum effect with benzylpenicillin. Similarly, Doern and Tubert ${ }^{5}$ observed inoculum effects for benzylpenicillin, ampicillin, cephalothin, cephamandole, cefuroxime and cefaclor for five $M$. catarrhalis strains that appeared susceptible to ampicillin at low inocula.

In the present investigation, $\beta$-lactamase-positive $M$. catarrhalis isolates exhibited an inoculum effect with ampicillin whereas $\beta$-lactamase-negative isolates did not. At an inoculum of $10^{4} \mathrm{cfu} / \mathrm{spot}$, many enzyme producers appeared as sensitive as non-producers

Table I. MICs of $\beta$-lactam antibiotics for different inocula of $M$. catarrhalis isolates with BRO-1 enzyme, BRO-2 enzyme or no $\beta$-lactamase

$\mathrm{MIC}(\mathrm{mg} / \mathrm{L})$ at an inoculum of

\begin{tabular}{|c|c|c|c|c|c|c|c|c|c|}
\hline \multirow{2}{*}{$\begin{array}{c}\text { Antimicrobial } \\
\text { agent }\end{array}$} & \multirow{2}{*}{$\begin{array}{c}\beta- \\
\text { Lactamase }\end{array}$} & \multicolumn{2}{|c|}{$10^{4} \mathrm{cfu} / \mathrm{spot}$} & \multicolumn{2}{|c|}{$10^{5} \mathrm{cfu} / \mathrm{spot}$} & \multicolumn{2}{|c|}{$10^{6} \mathrm{cfu} / \mathrm{spot}$} & \multicolumn{2}{|c|}{$10^{7} \mathrm{cfu} / \mathrm{spot}$} \\
\hline & & Range & $\begin{array}{c}\text { Geometric } \\
\text { mean }\end{array}$ & Range & $\begin{array}{c}\text { Geometric } \\
\text { mean }\end{array}$ & Range & $\begin{array}{c}\text { Geometric } \\
\text { mean }\end{array}$ & Range & $\begin{array}{c}\text { Geometric } \\
\text { mean }\end{array}$ \\
\hline \multirow[t]{3}{*}{ Co-amoxiclav } & BRO-1 & $0.008-0.25$ & 0.04 & $0.008-0.25$ & $0 \cdot 10$ & $0.03-0.25$ & $0 \cdot 10$ & $0.06-0.5$ & $0 \cdot 20$ \\
\hline & BRO-2 & $0.008-0.06$ & 0.01 & $0 \cdot 008-0 \cdot 12$ & 0.02 & $0.008-0.12$ & 0.02 & $0.03-0.25$ & $0 \cdot 10$ \\
\hline & None & $0.008-0.06$ & 0.01 & $0.008-0.06$ & $0 \cdot 01$ & $0.008-0.06$ & 0.01 & $0.008-0.06$ & 0.01 \\
\hline \multirow[t]{3}{*}{ Cefaclor } & BRO-1 & $0 \cdot 008-0 \cdot 5$ & $0 \cdot 20$ & $0 \cdot 25-1.00$ & $0 \cdot 60$ & $0.5-1.00$ & $0 \cdot 80$ & $0 \cdot 5-8 \cdot 00$ & $1 \cdot 40$ \\
\hline & BRO-2 & $0.008-1.0$ & $0 \cdot 30$ & $0.008-1.00$ & $0 \cdot 50$ & $0 \cdot 25-1 \cdot 00$ & 0.60 & $0 \cdot 5-2 \cdot 00$ & 1.00 \\
\hline & None & $0.008-0.5$ & $0 \cdot 20$ & $0.008-0.5$ & $0 \cdot 30$ & $0.25-1.00$ & $0 \cdot 50$ & $0 \cdot 5-1 \cdot 00$ & 0.60 \\
\hline \multirow[t]{3}{*}{ Cefixime } & BRO-1 & $0.008-0.25$ & $0 \cdot 10$ & $0.06-0.5$ & $0 \cdot 20$ & $0 \cdot 06-1 \cdot 00$ & $0 \cdot 40$ & $0 \cdot 12-2 \cdot 00$ & 0.60 \\
\hline & BRO-2 & $0.008-0.12$ & 0.02 & $0.008-0.25$ & $0 \cdot 10$ & $0 \cdot 06-0 \cdot 25$ & $0 \cdot 10$ & $0.06-0.25$ & $0 \cdot 10$ \\
\hline & None & $0.008-0.06$ & 0.03 & $0.03-0.5$ & $0 \cdot 10$ & $0.06-0.5$ & $0 \cdot 10$ & $0 \cdot 06-1 \cdot 00$ & $0 \cdot 10$ \\
\hline \multirow[t]{3}{*}{ Cefetamet } & BRO-1 & $0.008-1.00$ & $0 \cdot 50$ & $0.25-1.00$ & $0 \cdot 70$ & $0.25-1.00$ & 0.80 & $0 \cdot 5-1 \cdot 00$ & $0 \cdot 80$ \\
\hline & BRO-2 & $0.008-1.00$ & 0.50 & $0 \cdot 25-1 \cdot 00$ & $0 \cdot 70$ & $0.5-1.00$ & $0 \cdot 80$ & $0 \cdot 5-2 \cdot 00$ & 1.00 \\
\hline & None & $0 \cdot 008-1 \cdot 00$ & $0 \cdot 40$ & $0 \cdot 5-1 \cdot 00$ & $0 \cdot 80$ & $0.05-1.00$ & 0.90 & $0 \cdot 5-2 \cdot 00$ & 1.00 \\
\hline
\end{tabular}


Table II. Correlation coefficients between inhibition zones and the MICs obtained for different inocula of $M$. catarrhalis

\begin{tabular}{|c|c|c|c|c|}
\hline \multirow{2}{*}{$\begin{array}{l}\text { Antimicrobial } \\
\text { agent } \\
\text { (disk content) }\end{array}$} & \multicolumn{4}{|c|}{ MIC test inoculum (cfu/spot) of } \\
\hline & $10^{4}$ & $10^{5}$ & $10^{6}$ & $10^{7}$ \\
\hline Ampicillin $(2 \mu \mathrm{g})$ & 0.75 & $0 \cdot 88$ & $0 \cdot 88$ & 0.89 \\
\hline Co-amoxiclav $(2+1 \mu \mathrm{g})$ & 0.64 & $0 \cdot 65$ & 0.67 & 0.72 \\
\hline Cefaclor $(30 \mu \mathrm{g})$ & $0 \cdot 10$ & 0.29 & $0 \cdot 45$ & 0.50 \\
\hline Cefixime $(5 \mu \mathrm{g})$ & 0.50 & 0.63 & 0.69 & 0.63 \\
\hline Cefetamet $(10 \mu \mathrm{g})$ & $0 \cdot 10$ & $0 \cdot 20$ & $0 \cdot 16$ & $0 \cdot 17$ \\
\hline
\end{tabular}

whereas their resistance was apparent at an inoculum of $10^{7} \mathrm{cfu} /$ spot. At the latter inoculum the MICs for BRO-1 enzyme producers and non-producers were distinct, and there was little overlap even between isolates with BRO-1 and those with BRO-2. Apparent susceptibility of $\beta$-lactamase producers in tests with low inocula has been reported by others ${ }^{7}$ and contrasts with the ineffectiveness of ampicillin in infections caused by these organisms. ${ }^{8}$

Although BRO-2 producers were generally less resistant to ampicillin than those with BRO-1 enzyme, they did not show greater inoculum effects. The observation contrasts with the finding of Doern and Tubert ${ }^{5}$ that inoculum effects in broth dilution MIC titrations were greater for those $\beta$-lactamase producers that appeared most susceptible at low inocula.

A small $\beta$-lactamase-related inoculum effect was also seen for co-amoxiclav but no $\beta$-lactamase-related inoculum effect occurred for any of the cephalosporins tested, despite the fact that MIC data suggested that one or both BRO enzymes gave marginal protection against cefixime and cefaclor. Inoculum effects that were unrelated to $\beta$-lactamase production were seen for cefixime and cefaclor, although not for cefetamet.

\section{References}

1. Jorgensen JH, Doern GV, Maher LA, Howell AW, Redding JS Antimicrobial resistance among respiratory isolates of Haemophilus influenzae, Moraxella catarrhalis, and Streptococcus pneumoniae in the United States. Antimicrob Agents Chemother 1990; 34: 2075-2080.

2. Fung CP, Powell M, Seymour A, Yuan M, Williams JD. The antimicrobial susceptibility of Moraxella catarrhalis isolated in England and Scotland in 1991. J Antimicrob Chemother 1992; 30: 47-55.

3. Luman I, Wilson RW, Wallace RJ, Nash DR. Disk diffusion susceptibility of Branhamella catarrhalis and relationship of $\beta$-lactam zone size to $\beta$-lactamase production. Antimicrob Agents Chemother 1986; 30: 774-776.

4. Percival A, Corkill JE, Rowlands J, Sykes RB. Pathogenicity of and $\beta$-lactamase production by Branhamella (Neisseria) catarrhalis. Lancet 1977; 2: 1175.
Eliasson and $\mathrm{Kamme}^{9}$ also observed an inoculum effect with cefaclor for both enzyme-producers and non-producers. The mechanism(s) of these effects are unknown.

Correlation coefficients between MICs and the inhibition zones of disks were calculated solely to determine whether the degree of correlation was influenced by the inoculum size, as had been found in earlier investigations of methicillin-susceptible staphylococci tested against various cephalosporins and $\beta$-lactamase inhibitors. For the $M$. catarrhalis isolates examined in the present study there was little general relationship between inoculum size and the degree of correlation: the correlation coefficients for ampicillin and co-amoxiclav increased only marginally as the MIC inoculum was raised; that for cefaclor rose markedly, but remained below the accepted threshold of significance $(r=0.7)$. Correlation coefficients for cefetamet and cefixime varied inconsistently with the inoculum. The low correlation coefficients, notably for cefaclor and cefetamet, raise the question of the validity of disk tests with these compounds for predicting the clinical susceptibility of $M$. catarrhalis. However, at most inoculum levels, the MICs of these compounds were tightly clustered and high correlation coefficients are unlikely to be achieved under such conditions. Therefore, these findings merely show that the degree of correlation was not substantially inoculum dependent, and do not provide a rigorous examination of the validity of disk tests with these compounds, which would demand inclusion of isolates with a broader range of MICs.

The present data suggest that MICs of ampicillin for $M$. catarrhalis should be measured with much higher inocula than are conventionally used, but that this precaution is unnecessary with newer cephalosporins, despite the suggestion that BRO-1 enzyme may give slight protection against these compounds.

5. Doern GV, Tubert TA. Effect of inoculum size on results of macrotube broth dilution susceptibility tests with Branhamella catarrhalis. J Clin Microbiol 1987; 25: 1576-1578.

6. Fung CP, Yeo SF, Livermore DM. Susceptibility of Moraxella catarrhalis isolates to $\beta$-lactam antibiotics in relation to their $\beta$-lactamase pattern. $J$ Antimicrob Chemother (in press).

7. Wallace RJ, Nash DR, Steingrube VA. Antibiotic susceptibilities and drug resistance in Moraxella (Branhamella) catarrhalis. Am J Med 1990; 88 Suppl 5A: 46S-50S.

8. Wald ER, Rohn DD, Chiponis DM, Blatter MM, Reisinger KS, Wucher FP. Quantitative cultures of middle-ear fluid in acute otitis media. J Pediatr 1983; 102: 259-261.

9. Eliasson I, Kamme C. Characterization of the plasmidmediated- $\beta$-lactamase in Branhamella catarrhalis, with special reference to substrate affinity. J Antimicrob Chemother $1985 ; 15$ : 139-149. 